\title{
An Open Tutorial for Beginning Ancient Greek
}

\author{
Jeff Rydberg-Cox
}

University of Missouri-Kansas City

\begin{abstract}
For the past three years, I have been developing an open online digital tutorial for Ancient Greek designed for beginners with no previous knowledge of the language. This tutorial is available online at http://daedalus.umkc.edu/ FirstGreekBook. The drill and practice exercises in this tutorial are designed to engage a broad public audience both inside and outside traditional university classroom settings. The techniques and approaches used for syntactic annotation and translation alignment that are discussed in the articles about the Perseids Platform and the Treebanking environment elsewhere in this volume have informed the pedagogical approach of this tutorial.

In calendar year 2014, there were 15,178 unique visitors who viewed tutorial pages some 58,137 times. This chapter will explore patterns of data usage and describe the audiences that have been using the tutorial.

Digital tutorial programs for other languages such as Duolingo or Rosetta Stone successfully engage large audiences outside of traditional academic environments while most resources for the study of Ancient Greek are designed for use within traditional classrooms. An understanding of the usage patterns for this one digital tutorial will help illuminate ways that pedagogical materials can be crafted in order to engage with broader audiences.
\end{abstract}

How to cite this book chapter:

Rydberg-Cox, J. 2016. An Open Tutorial for Beginning Ancient Greek. In: Bodard, G \& Romanello, M (eds.) Digital Classics Outside the Echo-Chamber: Teaching, Knowledge Exchange \& Public Engagement, Pp. 69-82. London: Ubiquity Press.

DOI: http://dx.doi.org/10.5334/bat.e. License: CC-BY 4.0. 


\section{Introduction}

Being a professor of Classics is often a paradoxical position. Enrollments in Classics courses are often not large enough to justify offering courses in Greek and Latin and many programs have faced closure due to low student numbers. The Modern Language Association's 2015 report on enrollments in language courses reports a $35 \%$ decline in the number of students enrolled in Ancient Greek and a 16\% drop in the number of students enrolled in Latin in the since 2009. ${ }^{1}$ A recent article in Inside Higher Education describes an enrollment pattern in Greek and Latin courses at Centenary College that will sound familiar to many classicists. 'Enrollments of five to seven students are good for upper division courses and most years there are only a few majors, sometimes just one.2

Despite low enrollments in university classes, the ongoing presence of Ancient Greece and Rome in popular culture generates a steady stream of students who are interested in the study of Greek and Latin and also a population of adults outside the university who are interested in studying these languages for personal interest and enrichment. These two populations who desire to study Greek or Latin live 'outside the echo chamber' because they do not participate in the intellectual life of larger universities that draw a substantial enough student population to justify offering Greek and Latin. There are certainly resources available for these populations such as the independent study guide to the Joint Association of Classics Teachers Ancient Greek curriculum. There are also online resources that are connected to textbooks such as Maurice Balme and Gilbert Lawall's Athenaze, Donald Mastronarde's Introduction to Attic Greek, Cecila' Lusching's An Introduction to Ancient Greek: A Literary Approach and Anne Groton's Ancient Greek: A Literary Approach. ${ }^{3}$ While these online resources are all connected to textbooks that are designed to be used within a traditional university classroom, there are fewer resources that will allow these groups to study Ancient Greek entirely online and entirely on their own.

A great deal of my digital work for the past three years has been devoted to developing this sort of online tutorial. With 15,178 unique visitors who viewed tutorial pages some 58,137 times in 2014, the tutorial has reached a broader audience than I ever expected and proven to be an effective mechanism for those students and lifelong learners who live outside the echo chamber to study Ancient Greek.

\section{A Brief Overview of the Tutorial}

In its current instantiation, the tutorial consists of an interactive version of John William White's First Greek Book that reimagines a late $19^{\text {th }}$-century textbook as a digital workbook. ${ }^{4}$ White's original book contains eighty chapters with 
each introducing an element of syntax and morphology alongside vocabulary and guided readings that are designed to lead students to the ability to independently read Xenophon's Anabasis. The digital tutorial is available online at http://daedalus.umkc.edu/FirstGreekBook.

The tutorial consists of 84 static HTML pages that preserve the original textbook's basic structure. The HTML pages also include multiple-choice quizzes that allow students to memorize vocabulary, declensions and conjugations. The vocabulary and grammatical paradigms from each chapter are also available for download as tab delimited UTF8 files so that users can import the data into flashcard programs or use the data for other purposes. The tutorial is open access in two senses; first it is freely available for use online by any interested individual and-as of the summer of 2015-all of the material is also available for download, extension, and reuse under a Creative Commons Non-Commercial-By Attribution-Share Alike license.

The tutorial also includes two types of translation exercise built around the sample readings in White's original tutorial. As illustrated in Figure 1, the first translation exercise asks users to match words or phrases from the Greek with the corresponding word or phrase in an English translation. The second translation exercise shown to the left asks students to identify the grammatical role of each word in the sample sentences. Both of these translation practice exercises were inspired by the work of the Alpheios project and the Perseids Platform that are described elsewhere in this volume. ${ }^{5}$ The approach of matching words with their correct translation is an extremely simplified version of the Alpheos translation alignment tool that allows readers to match words and phrases in a passage with their equivalents in a translation. ${ }^{6}$ The exercises that ask students to identify the grammatical role for each word in a sentence is inspired by the Perseids treebanking project that is also described elsewhere in this volume. The inspiration for the tutorial itself, in fact, came out of a class in

\section{REVIEW AND PRACTICE:}

You have correctly answered 1 out of 20 total questions.

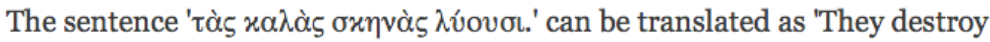
the beautiful tents.' In this sentence, what is the best translation of $x \alpha \lambda$ às?

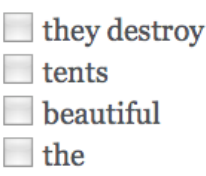

Figure 1: Sample translation exercise. 
which I was asking beginning students to work on treebanks and realized the need for an approach that would lead learners with absolutely no knowledge of Ancient Greek to a point where they could reasonably begin to create treebanks for existing texts.

These exercises are supplemented by a gamified system that helps readers track the material that they have learned and what material is ready for review. ${ }^{7}$ In this system, users can earn virtual drachmas as they work through the exercises. These drachmas serve as markers of progress rather than a virtual currency that can be used to purchase add-ons or additional exercises as one can with Duolingo's lingots. There are ten drachmas available in each chapter and users earn one drachma every time they correctly answer ten percent of the questions in that unit. The tutorial employs local storage in the users' browser to keep track of the questions that have been answered correctly and to prompt users to review material on a spaced repetition schedule. If a user answers a question correctly on day 1 , he or she is prompted to review that question on day 2. If it is answered correctly, they are then prompted to review it again on day 4 , day 8 , day 16 , etc. If at any point, they answer the question incorrectly, the period until its next review returns to one day. The number of drachmas that are shown for each chapter corresponds to the number of questions that are ready for review. If users do not see the full complement of drachmas for a chapter that they have already studied, they know that they need to review the material in this chapter.

The tutorial is designed to work on mobile browsers with a minimal responsive design (see Figure 2). By default, the tutorial is designed to fit into a width of 768 pixels, so that it displays the same way in both desktop browsers and on tablets such as the iPad or Kindle Fire. In smaller form factors, the font size shrinks but the interface remains fundamentally the same. While this design means that the tutorial does not take advantage of the possibilities of different types of pedagogical exercises that would be possible on a larger screen with a physical keyboard, it does respond to the necessities of small shop digital humanities, where software development time is balanced between teaching, service and other research duties. Design simplicity ensures that the tutorial can function without the need for any additional server software, security updates, or reconfigurations as new tablet form factors are introduced.

The drachma system is implemented using the local storage function of HTML5 and so it is limited to a single browser on a single device. If a user wants to use the tutorial from both a mobile device and a desktop, the drachma system does not carry over. While the ability for a user to track their progress on more than one device would perhaps be the most useful enhancement to the tutorial, the considerations of design simplicity and small shop digital humanities have led to this decision at the current time. Tracking user activity across devices would require the creation of user accounts and passwords that must be stored and maintained on a server. Once again, my focus on design simplicity and the lack of a full time system administrator who can ensure security 
daedalus.umkc.edu

\section{Formation Of Adjectives}

77. The masculine and neuter of the adjectives thus far given follow the O-Declension, the feminine the A-Declension. The nominative singular, therefore, ends in os, $\eta$ or $\bar{\alpha}$, ov (Latin us, a, um), as follows:

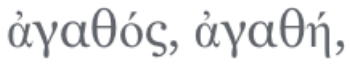
àyäóv

good.

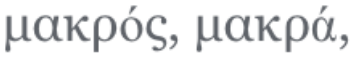
накрóv

long.

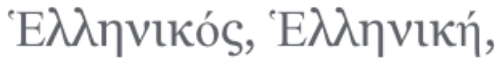

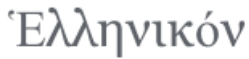

Greek.

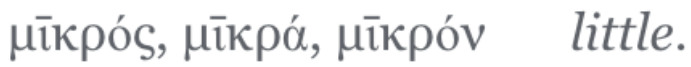

какós, какท́, какóv

bad, cowardly.

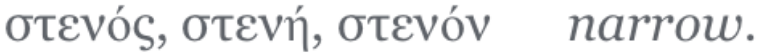

<--Lesson 7 Vocabulary Settings Table of Contents

Figure 2: Tutorial lesson on a mobile device. 
and constant uptime has led to the decision rely solely on local storage for the tracking system.

\section{Who Uses the Tutorial}

While I do use this tutorial as part of my traditional university classroom, as an open-access resource it has also reached many more people than I could reach in my classroom. The decision not to require user accounts makes it more difficult to understand how people are using the tutorial. I do not have direct access to information about how often specific individuals access the tutorial, how long they use it once they begin, how far they are able to progress through the tutorial before they lose interest, etc. Despite the lack of individual user data, information provided by Google Analytics provides some insight into the nature of the audience for this tutorial.

In calendar year 2014, some 15,178 unique individuals viewed 58,137 pages in the tutorial. As shown in Figure 3, tutorial users primarily reside in the United States (57.75\%) with other users in the United Kingdom (7.8\%), Australia (4.4\%), Canada (3.7\%), Brazil (2\%), Germany (1.7\%), Greece (1.4\%), India (1.3\%), Italy (1.2\%) and Spain (1\%).

While there is no easy way to determine how many of these users are traditional students, data about internet service providers might provide a proxy. According to Google Analytics, the top internet service provider for nonmobile traffic with $6 \%$ of the traffic is 'not set.' The next seven most common service providers that account for twenty two percent of the tutorial sessions are major American internet service providers such as Time Warner Cable, AT\&T, Verizon and Comcast indicating that a good percentage of the users are accessing the tutorial outside the confines of a traditional educational institution. Of course, one cannot tell whether these are students doing homework away from campus or learners outside of the echo chamber, but it certainly does suggest that there are not large clusters of university students using the tutorial from their dormitories. The first identifiable educational institution does not appear on the list of most common service providers until number forty and this institution accounted for only .29\% of the traffic for the calendar year 2014. In the list of the top one hundred of most common service providers, there are only eleven identifiable educational institutions and these taken together account for just $2 \%$ of the total traffic in the same period.

Further, while $98 \%$ of the tutorial users are using computers that are not connected to the internet on a traditional campus, their usage pattern over time only partially reflects the ebb and flow of the academic year. There are noticeable peaks in July and at the end of the year, months when one might expect a decline due to holiday schedules if the primary audiences for the tutorial were located within traditional academic institutions (see Figure 4). 


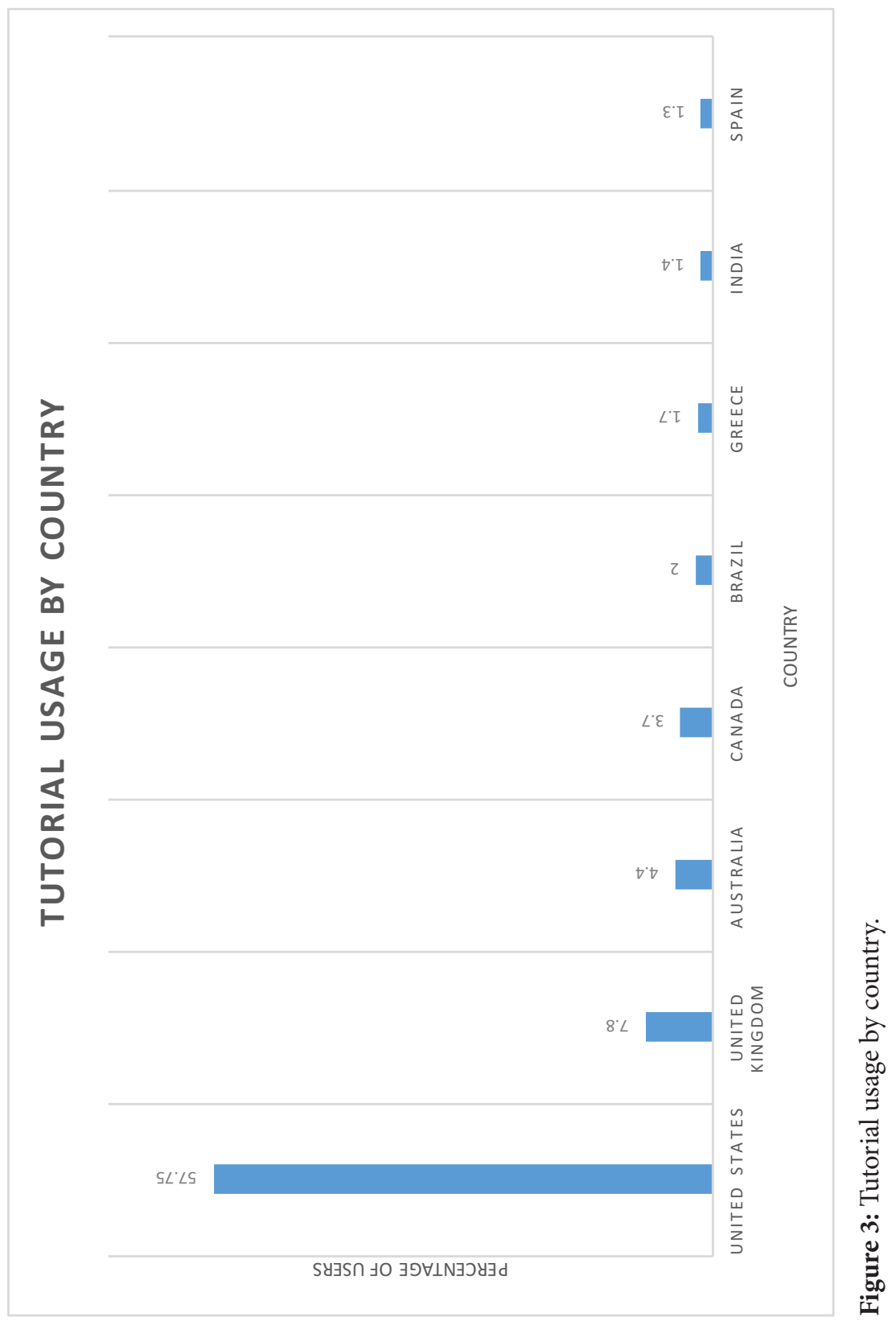




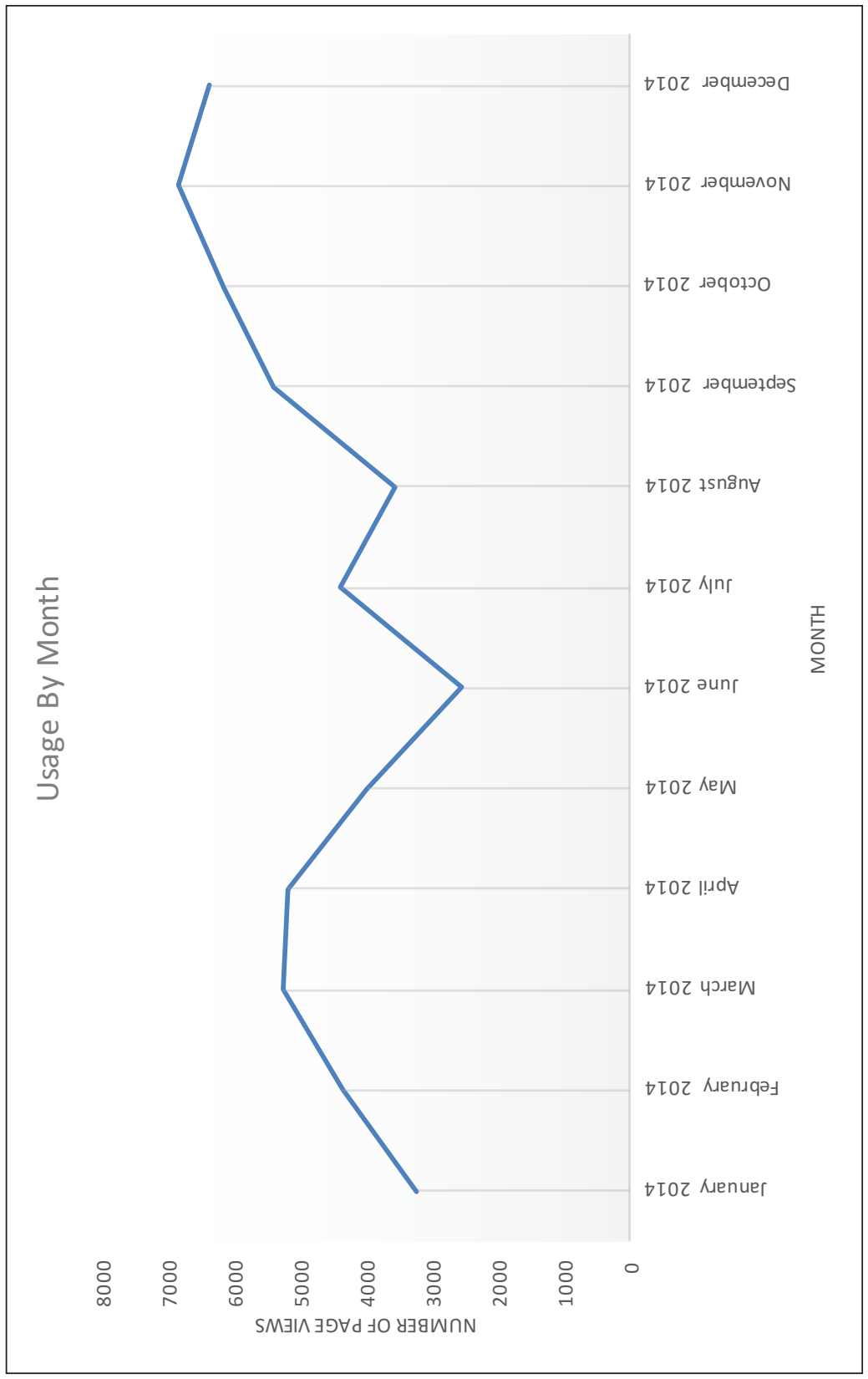




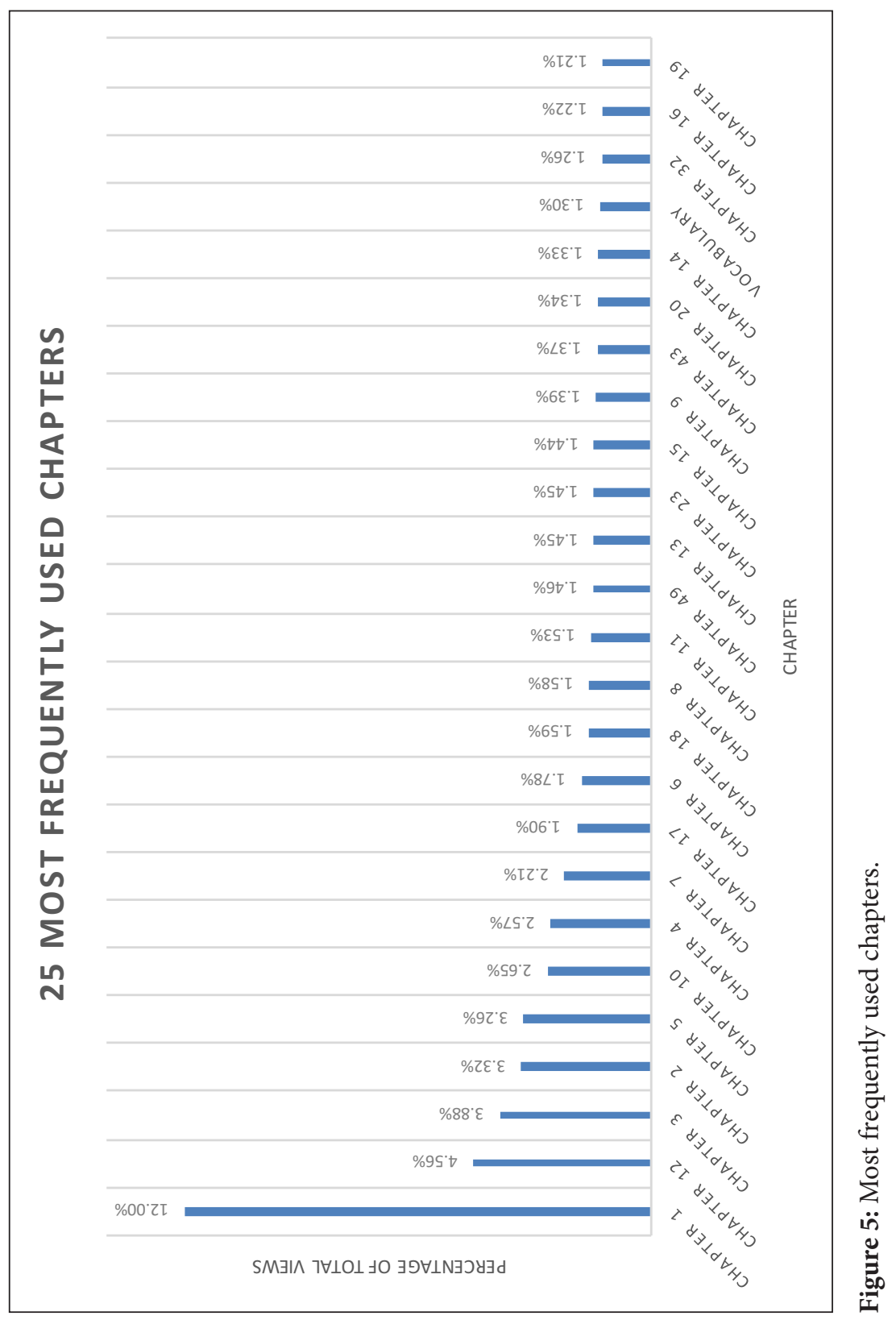


The pattern of usage for the individual chapters shows that more users start the book than complete it with a noticeable drop off somewhere around the 10th chapter (Figure 5). The earlier chapters are used more frequently than the later ones, but the decline is not linear in relation to the chapter numbers. The data show that many people browse only the first chapter. Chapters two through fifteen all appear in the list of the top 25 most frequently visited chapters alongside an assortment of chapters from the first half of the book.

Table 1 shows that the spread among chapter usage after the first few chapters is very small; this suggests that there are four types of users: users who browse the first chapter and decide not to use the tutorial further, a larger cohort who get through approximately 15 chapters and then trails off, a middle group of users who get about halfway through the tutorial and a smaller group of users who complete the entire tutorial.

This distribution also suggests that the tutorial is reaching an audience outside of traditional classrooms because there are no clear break points at the chapters where one might expect them if the tutorial were being used in a two or three semester Ancient Greek sequence.

One of the design goals for this tutorial was to make it usable from mobile devices in addition to computer web browsers. As I was engaged in the initial planning of this project, I noticed that many e-learning content management systems offered only minimal functionality to mobile users even it seemed that progressively more of my students were wanting to access them using mobile devices. The usage data bear this out but not perhaps to the extent that I might have expected; roughly one third of the users access the tutorial using a mobile operating system. More interesting, however, is the apparent equal division between phone-sized platforms and tablets in the usage data. Roughly half

\begin{tabular}{|c|c|c|}
\hline $\begin{array}{l}\text { Percent of Page } \\
\text { Views }\end{array}$ & $\begin{array}{c}\text { Number of Chapters } \\
\text { in Range }\end{array}$ & $\begin{array}{c}\text { Chapters in Range (in descending } \\
\text { order) }\end{array}$ \\
\hline $12 \%$ & 1 & 1 \\
\hline $2 \%-5 \%$ & 7 & $12,3,2,5,4,7$ \\
\hline $1 \%-1.99 \%$ & 19 & $\begin{array}{c}17,6,18,8,11,49,13,23,15,9,43,20,14, \\
\text { Vocabulary, } 32,16,19,21,24\end{array}$ \\
\hline$<1 \%$ & 59 & $\begin{array}{c}\text { Flashcards, } 28,22,30,25,40,31,38,48, \\
\text { Appendix, 26, 34, 29, 27, 37, 33, 79, 52, } \\
\text { 50, 44, 39, 80, 41, 57, 47, 53, 35, 36, 56, } \\
\text { 75, 65, 42, 45, 74, Settings, 46, 55, 76, } \\
\text { 71, 51, 58, 60, 78, 66, 73, 77, 59, 70, 54, } \\
\text { 61, 63, 67, Contract Rules, } 62 \text {, Contract } \\
\text { Nouns, } 72,64,68,69\end{array}$ \\
\hline
\end{tabular}

Table 1: Distribution of chapter usage throughout the Greek tutorial. 
of the mobile operating system sessions with the tutorial were initiated using devices with phone-sized screen resolutions and the other half were initiated using tablets.

\section{Conclusions}

The usage data for this tutorial shows that there is a sizable population of readers who are not affiliated with universities who are interested in studying ancient languages. This follows a pattern of use that also appears for other online scholarly resources. Gregory Crane more than fifteen years ago pointed out that the Perseus Digital Library saw a spike in users outside of educational institutions at lunch hours and in the evenings. ${ }^{8}$ More broadly this reflects the pattern of usage for online materials that Chris Anderson described in 2004 as the 'Long Tail.' Anderson describes how physical media such as books or DVDs could only be stocked in a brick-and-mortar store if it could 'generate sufficient demand to earn its keep.9 Further, since an item had to generate this demand from a limited geographic area, a film or a book could only be available in areas with a high concentration of interested consumers. Those who lived outside these echo chambers that lacked a sufficient population who shared their interests had difficulties gaining access to these items. The long tail describes the phenomenon whereby online access allows geographically dispersed communities of users to emerge in sufficient numbers to support the development of material that might not be viable in an environment that depends on physical access.

It is not at all difficult to imagine the traditional university as one of Anderson's brick-and-mortar stores. The physical university has served the function of concentrating people who are interested in a specific topic into a physical location in sufficient numbers to support the creation of courses, books, articles, etc. about these areas of interest. Textbooks, monographs and other research publications were largely designed based on the assumption that they would be consumed within such a geographically concentrated community. This is still the case today; many fine textbooks are still being written in such a way that they would only be useful to a student who is using them in a traditional classroom setting in consultation with a trained professional. Other resources for learning modern languages such as Babbel, Duolingo, Lang-8, etc. have provided clear models for self-directed language pedagogy and large geographically dispersed communities of interest have formed around these resources. In a time when the university is no longer serving to gather people interested in the study of the ancient world together in sufficient numbers to support classes, should we begin to wonder if the paradoxically positioned Classics professor might be best served by turning their attention towards developing resources and programs that leverage the long tail of people who are interested in the study of the ancient world? 
Further, a tutorial such as this one can also serve as a building block for a program of broader participation in Classical research on the citizen science model. The Ancient Greek and Latin Dependency Treebank and the Perseids project described elsewhere in this volume provide a robust environment for citizen philologists to make concrete and real contributions to the study and understanding of Ancient Greek and Latin. While Perseids and the Treebank project have developed programs for students and citizen philologists to gain the basic skills required to participate in these projects, wholly independent tutorials such as this one provide another avenue for students and scholars who work outside of the echo chamber of traditional universities to gain the baseline skills required to contribute to projects such as these.

\section{Notes}

${ }^{1}$ Goldberg, Looney \& Lusin 2015. See also Flaherty 2015.

${ }^{2}$ Jaschik 2015. Beard 2012 offers an insightful discussion of the 'End of Classics'.

${ }^{3}$ Joint Association of Classical Teachers 2008, Blama, Lawall \& Morwood 2014; Groton 2013; Luschnig \& Mitchell 2007; Mastronarde 2013. Rebecca Frost Davis offers a discussion of available resources at $<$ https://rebecca frostdavis.wordpress.com/2013/05/24/challenges-of-blended-learning-inthe-humanities-ancient-greek/> and <https://rebeccafrostdavis.wordpress. com/2013/05/28/challenges-of-blended-learning-in-ancient-greek-followup/> while Toon Van Hall offers a directory of resources at $<$ http://greek grammar.wikidot.com/introductory-courses $>$.

4 This tutorial has been described in more detail in Rydberg-Cox 2013.

${ }^{5}$ For more details on the treebanking and Alpheos projects, see Bamman and Crane 2007; Bamman and Crane 2006; Bamman et al. 2009.

${ }^{6}$ Available at <http://alpheios.net> under 'Apheios Alignment Editor'.

${ }^{7}$ For conversations about gamification and pedagogy, see Kapp 2012; Landers a \& Callan 2011; and Renaud \& Wagoner 2011.

${ }^{8}$ Crane 1998.

9 Anderson 2004, This article was expanded into the book Anderson 2006. For a discussion of the long tail and pedagogy, see Brown and Adler 2008.

\section{References}

Anderson, C. (2004, October). The Long Tail. Wired Magazine 12(10).

Anderson, C. (2006) The Long Tail: Why the Future of Business Is Selling Less of More (Hachette Digital, Inc.). 
Balme, M., Lawall, G. \& Morwood, J. (2014). Athenaze, Book I: An Introduction to Ancient Greek. 3rd Edition. Oxford: Oxford University Press.

Bamman, D. \& Crane, G. (2006). The Design and Use of a Latin Dependency Treebank. In Proceedings of the Fifth Workshop on Treebanks and Linguistic Theories (TLT2006), pp. 67-78.

Beard, M. (2012, January 12) Do the Classics Have a Future? The New York Review of Books. Retrieved from http://www.nybooks.com/articles/ archives/2012/jan/12/do-classics-have-future/

Brown, J. S. \& Adler, R. P. (2008). Open Education, the Long Tail, and Learning 2.0. Educause Review 43(1): 16-20.

Crane, G. (1998). New Technologies for Reading: The Lexicon and the Digital Library. The Classical World 91(6): 471-501.

David, B. \& Crane, G. (2007). The Latin Dependency Treebank in a Cultural Heritage Digital Library. ACL, 33.

David, B., Mambrini, F. \& Crane, G. (2009). An Ownership Model of Annotation: The Ancient Greek Dependency Treebank. In Proceedings of the Eighth International Workshop on Treebanks and Linguistic Theories (TLT8). Milan, Italy: EDUCatt, pp. 5-15.

Flaherty, C. (2015, February 11). MLA Report Shows Declines in Enrollment in Most Foreign Languages. Inside Higher Ed. Retrieved from https://www. insidehighered.com/news/2015/02/11/mla-report-shows-declinesenrollment-most-foreign-languages.

Goldberg, D., Looney, D. \& Lusin, N. (2015). Enrollments in Languages Other Than English in United States Institutions of Higher Education, Fall 2013. Retrieved from http://www.mla.org/pdf/2013_enrollment_ survey.pdf

Groton, A. H. (2013). From Alpha to Omega: A Beginning Course in Classical Greek. 4th Edition. Newburyport, MA: Focus.

Jaschik, S. (2015). Turning Off the Lights. Inside Higher Ed. Retrieved from https://www.insidehighered.com/news/2010/03/04/clark

Joint Association of Classical Teachers. (2008). An Independent Study Guide to Reading Greek. 2nd Edition. New York: Cambridge University Press.

Kapp, K. M. (2012). The Gamification of Learning and Instruction: Game-Based Methods and Strategies for Training and Education. Hoboken, NJ: John Wiley \& Sons.

Landers, R. N. \& Callan, R. C. (2011). Casual Social Games as Serious Games: The Psychology of Gamification in Undergraduate Education and Employee Training. In Serious Games and Edutainment Applications (pp. 399-423). New York: Springer. Retrieved from http://link.springer. com/chapter/10.1007/978-1-4471-2161-9_20

Luschnig, C. A. E. \& Mitchell. D. (2007). An Introduction to Ancient Greek: A Literary Approach. 2nd Edition. Indianapolis: Hackett Publishing Company, Inc. 
Mastronarde, D. J. (2013). Introduction to Attic Greek. Second Edition. Berkeley: University of California Press.

Renaud, C. \& and Wagoner, B. (2011). The Gamification of Learning. Principal Leadership 12(1): 56-59.

Rydberg-Cox, J. (2013). A Digital Tutorial for Ancient Greek Based on John Williams White's First Greek Book. Classical World 107(1): 111-17. 